\title{
Highly Enantioselective Catalytic Allylboration of Ketiminoesters: Practical and Scalable Synthesis of $\alpha$-Fully-Substituted Amino Esters
}

\author{
Urmibhusan Bhakta, ${ }^{\dagger}$ Padmanabha V. Kattamuri, ${ }^{\dagger}$ Juha H. Siitonen,${ }^{\dagger}$ Lawrence B. Alemany ${ }^{\# \dagger}$ and László Kürti ${ }^{\dagger *}$ \\ 'Department of Chemistry, Rice University, BioScience Research Collaborative, Houston, TX 77005, USA. \\ \#Shared Equipment Authority, Rice University, 6100 Main Street, Houston, TX 77005, USA. \\ KEYWORDS. Catalytic asymmetric allylboration, Chiral homoallylic amine, Chiral homoallylic aminoester, Trifluorometh- \\ ylated amino acid, Fully substituted stereocenter, Chiral pyrrolidine derivatives
}

\section{Supporting Information Placeholder}

\begin{abstract}
We report the first catalytic enantioselective allylboration of $\alpha$-ketiminoesters to afford chiral $\alpha$-allyl- $\alpha$-aryl and $\alpha$-allyl- $\alpha$-trifluoromethyl amino esters in excellent isolated yields and with high optical purity. This operationally simple allylation proceeds under ambient conditions with indium(I)-iodide/BOXtype ligand (5-10 mol\%) and can be performed on a gram scale. A proposed qualitative model for the high stereoselectivity indicates that the origin of selectivity is likely due to attractive interactions between the substrate and the BOX ligand. Using a different BOXtype ligand reverses the reaction's absolute sense of enantioselectivity. The allylated products are easily converted to enantiomerically enriched $\alpha$-substituted proline derivatives.
\end{abstract}

Enantioenriched $\alpha, \alpha$-di-substituted amino acids (e.g., $\alpha$-allyl- $\alpha$ aryl and $\alpha$-allyl- $\alpha$-trifluoromethyl) are important synthetic building blocks as they are readily diversified to densely functionalized structures prevalent in various natural products and pharmaceuticals. ${ }^{1,2}$ In particular, $\alpha$-allyl- $\alpha$-trifluoromethyl amino acid derivatives can be used to incorporate $\mathrm{CF}_{3}$ groups into active pharmaceutical ingredients (APIs) for desirable chemical, biological and physical properties. ${ }^{3}$ Another key feature of homoallylic $\alpha$-amino esters is their fully substituted stereogenic carbon center, which translates to increased stability under various physiological conditions. When incorporated into peptidomimetics, their resistance toward enzymatic degradation is significantly enhanced. . $^{4}$

Enantioenriched homoallylic $\alpha$-amino esters are prepared with asymmetric allylation of ketiminoesters. However, unlike wellstudied aldiminoesters, ${ }^{6}$ there are only a few examples of asymmetric allylation of ketiminoesters in the literature. ${ }^{7}$ Ketiminoesters, compared to aldiminoesters, are more challenging substrates as they are less reactive and their enantiofacial distinction at the prochiral $\mathrm{C}=\mathrm{N}$ site is lower. ${ }^{8}$ In 2014 , Kozlowski and co-workers reported a Pd-catalyzed asymmetric tandem alkylation/ $\alpha$-allylation of $\alpha$-aryl $\alpha$-iminoesters (Scheme 1A); yields and enantioselectivities ranged from moderate to very good. ${ }^{7}$ Recently, the Procter group developed a copper-catalyzed allylboration of $\alpha$-aryl $\alpha$-iminoesters utilizing an in situ-generated allylboronate reagent; the racemic products were obtained with moderate to high diastereoselectivities (Scheme 1B). ${ }^{9}$
Scheme 1: Allylation of Ketiminoesters:
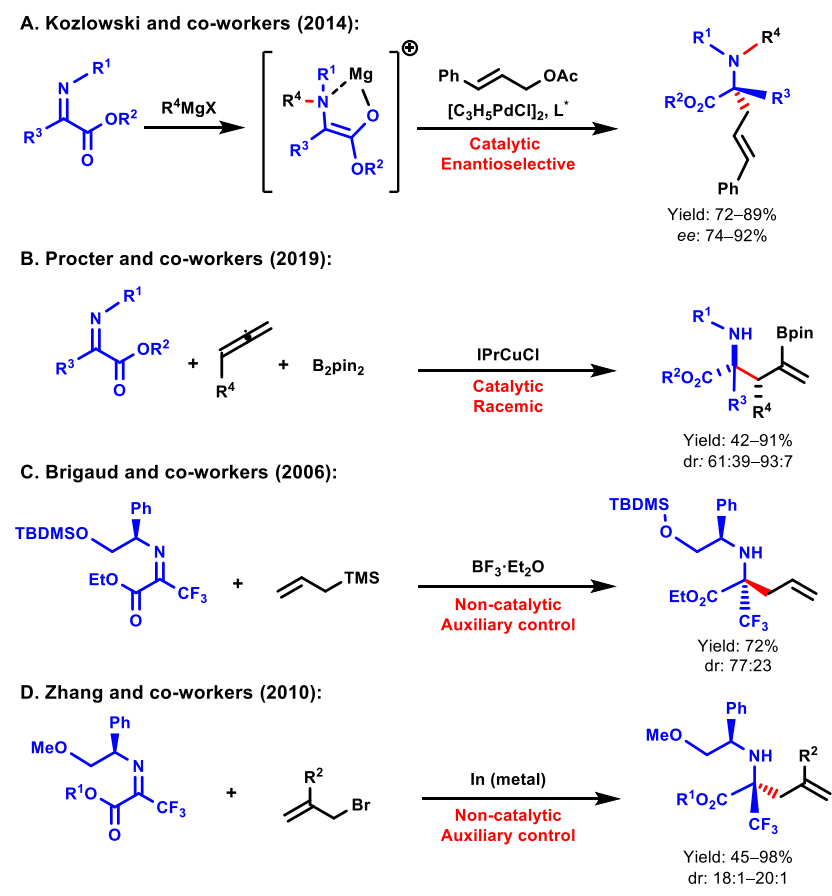

THIS WORK: Catalytic Enantioselective

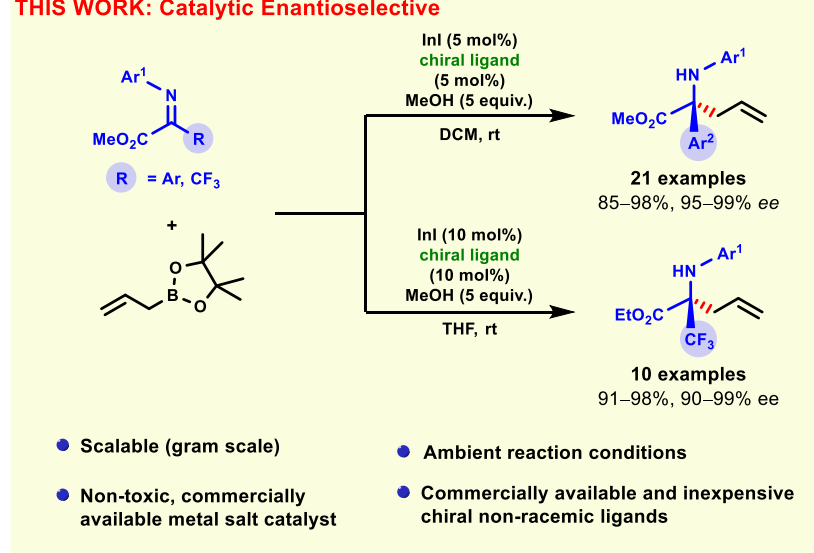


A diastereoselective, chiral auxiliary controlled allylsilylation of a enantioenriched $\alpha$-trifluoromethyl $\alpha$-iminoesters was reported by Brigaud et al. (Scheme 1C), ${ }^{10}$ while Zhang and co-workers disclosed a related diastereoselective allylindium addition using a similar auxiliary (Scheme 1D). ${ }^{11}$ There have also been reports (e.g., by Leighton ${ }^{12}$ and Juaristi ${ }^{13}$ ) on the asymmetric allylsilylation of ketoester hydrazones using stoichiometric enantiopure allylating reagents, albeit with narrow substrate scopes.

To the best of our knowledge, a general and direct catalytic asymmetric allylation of $\alpha$-aryl and $\alpha$-trifluoromethyl ketiminoesters is currently unknown. Herein, we demonstrate the use of chiral indium(I) catalysts featuring BOX-type ligands for the practical and scalable catalytic asymmetric allylboration of both $\alpha$-aryl- and $\alpha$ trifluoromethyl ketiminoesters. At the outset of our study, we applied a number of previously reported catalytic asymmetric allylation methods (e.g., Yamamoto, ${ }^{14}$ Shibasaki ${ }^{15}$ and Schaus ${ }^{16}$ who used $\mathrm{AgF}, \mathrm{CuF}$ and a BINOL-derivative as catalysts, respectively) to a model ketiminoester 1a. These methods were specifically developed for the allylation of aldimine and ketimine substrates with either allylsilanes or allylboronates. However, all of these conditions led to racemic product 3a when applied to substrate 1a (see SI p. 10).

Thus, we concluded that a mechanistically different allylation was needed. This could be achieved by employing main group metal salts, such as indium(I)iodide, as catalysts in lieu of transition metal complexes, as demonstrated by Kobayashi and co-workers for the catalytic allylboration of aldehyde acyl hydrazones. ${ }^{17}$ Indium compounds are also non-toxic and relatively cheap, further justifying this choice. ${ }^{17,18,19}$

In the Kobayashi-type allylation, a chiral allylic indium(I) complex is formed in situ via transmetallation of AllBpin. In the proposed transition state, both the acyl hydrazone and the BOX ligand ${ }^{20}$ bind to indium(I) in a bidentate mode, leading to a closed, six-membered Zimmerman-Traxler type transition state (I, Figure 1). We envisioned our ketiminoester substrate (1a) could also function as a bidentate ligand, leading to a similar transition state (II, Figure 1) and result in a high level of enantioinduction.

Figure 1: Initial Working Model for Allyl-Transfer
I.

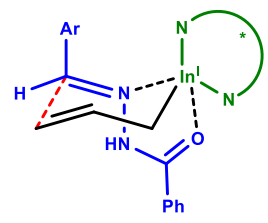

Kobayashi et al. (2010) Allylation of Aryl Aldehyde-Derived
Acylhydrazones

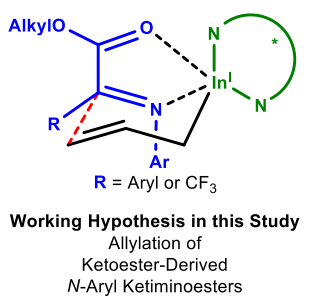

A thorough optimization of the reaction conditions was carried out (Table 1; See SI p. 11). These results confirmed that using a main group metal complex was indeed the right choice. Semicorrin $(\mathbf{C})$ (entries 14-18) emerged to be the best ligand partner. A $5 \mathrm{~mol} \%$ loading of InI with $5 \mathrm{~mol} \%$ ligand $\mathbf{C}$ in DCM with methanol as the key additive was the best combination for the asymmetric allylation of 1 a (entry 18, 94\% yield and 99\% ee). The methanol additive was required for the reaction to proceed; ethanol was found to be nearly equally good as an additive, however, in the presence of trifluoroethanol the allylation does not proceed. The screening also revealed that ligand $\mathbf{D}$ could reverse the stereoselectivity, so that the opposite enantiomer of the product (ent-3a) could be obtained in excellent yield and enantioselectivity (entry 19, 94\% yield and $-99 \%$ $e e)$.
Table 1: Screening the Conditions for Catalytic Asymmetric Allylation of Ketiminoester:
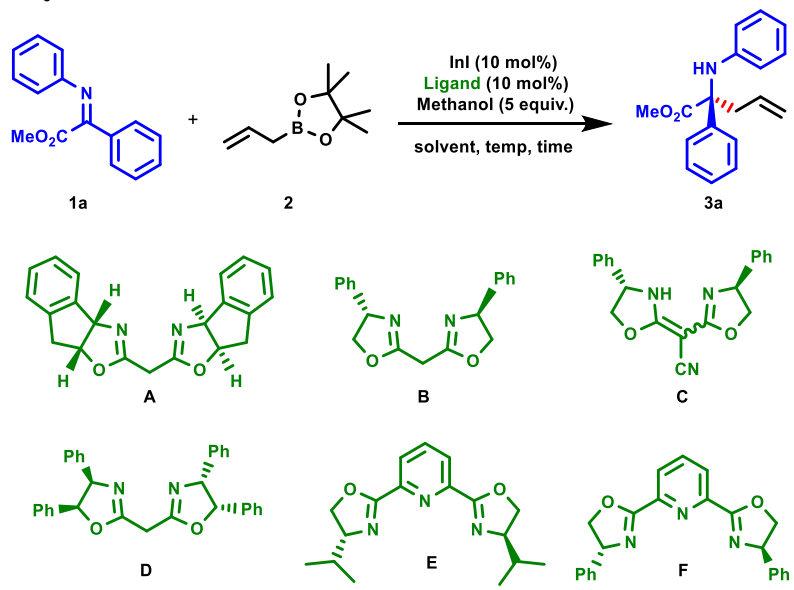

\begin{tabular}{|c|c|c|c|c|c|}
\hline Entry & Ligand $^{\mathrm{a}}$ & Solvent ${ }^{\mathrm{b}}$ & $\begin{array}{l}\text { Temp } \\
\text { (Time) }\end{array}$ & $\begin{array}{l}\text { Yield } \\
(\%)\end{array}$ & $e e(\%)$ \\
\hline 1 & (R)-BINAP & THF & rt (24 h) & 77 & rac \\
\hline 2 & $(R)$-SEGPHOS & THF & rt (24 h) & 67 & rac \\
\hline 3 & (R)-DIFLUOPHOS & THF & rt (24 h) & 75 & rac \\
\hline 4 & $\mathbf{A}$ & Toluene & rt (24 h) & - & - \\
\hline 5 & $\mathbf{A}$ & THF & rt (24 h) & 85 & 64 \\
\hline 6 & $\mathbf{A}$ & DCM & rt $(26 \mathrm{~h})$ & 86 & 67 \\
\hline 7 & $\mathbf{A}$ & $\mathrm{Et}_{2} \mathrm{O}$ & rt $(36 \mathrm{~h})$ & 86 & 58 \\
\hline 8 & A & THF & $-5^{\circ} \mathrm{C}(80 \mathrm{~h})$ & 82 & 65 \\
\hline 9 & $\mathbf{A}$ & DCM & $-5^{\circ} \mathrm{C}(80 \mathrm{~h})$ & 82 & 71 \\
\hline 10 & B & THF & rt (11 h) & 88 & 95 \\
\hline 11 & B & DCM & rt $(19 \mathrm{~h})$ & 90 & 97 \\
\hline 12 & B & $\mathrm{Et}_{2} \mathrm{O}$ & rt (24 h) & - & - \\
\hline 13 & B & DME & rt (24 h) & - & - \\
\hline 14 & C & THF & rt (12 h) & 90 & 96 \\
\hline 15 & C & DCM & rt (12 h) & 93 & 99 \\
\hline 16 & C & $\mathrm{DCM}^{\mathrm{c}}$ & rt (12 h) & 90 & 99 \\
\hline 17 & C & $\mathrm{DCM}^{\mathrm{d}}$ & rt (12 h) & 88 & 99 \\
\hline 18 & $\mathbf{C}^{\mathrm{e}}$ & $\mathbf{D C M}^{\mathbf{b}}$ & rt (12 h) & 94 & 99 \\
\hline 19 & $\mathbf{D}^{\mathrm{e}}$ & $\mathrm{DCM}^{\mathrm{b}}$ & rt $(9 \mathrm{~h})$ & 95 & -99 \\
\hline 20 & $\mathbf{E}^{\mathbf{e}}$ & $\mathrm{DCM}^{\mathrm{b}}$ & rt $(26 \mathrm{~h})$ & 82 & rac \\
\hline 21 & $F^{e}$ & $\mathrm{DCM}^{\mathrm{b}}$ & rt (27 h) & 79 & $r a c$ \\
\hline
\end{tabular}

Conditions: Unless otherwise stated, $0.5 \mathrm{mmol}$ of $\mathbf{1 a}$, the ligand (10 $\mathrm{mol} \%)$ and $\mathrm{InI}(10 \mathrm{~mol} \%)$ were added in $1.5 \mathrm{~mL}$ solvent $(0.33 \mathrm{M})$. Next, $0.75 \mathrm{mmol}$ of 2 was added to the reaction mixture along with $\mathrm{MeOH}(2.5$ mmol). The progress of the reaction was monitored by TLC. All yields are isolated yields. The enantiomeric excesses were determined by HPLC on chiral stationary phase. ${ }^{\mathrm{a}} 10 \mathrm{~mol} \%$ of ligand with $10 \mathrm{~mol} \%$ of InI; ${ }^{\mathrm{b}} 0.33$ $\mathrm{M} ;{ }^{\mathrm{c}} 0.16 \mathrm{M}$; ${ }^{\mathrm{d}} 0.66 \mathrm{M}$; ${ }^{\mathrm{s}} 5 \mathrm{~mol} \%$ of ligand with $5 \mathrm{~mol} \%$ of InI.

With the optimized conditions in hand, we explored the scope of substrates. Twenty $\alpha$-aryl $\alpha$-ketiminoesters (1b-1u), featuring both electron-withdrawing and donating-substitutents were evaluated (Table 2). In all the cases, excellent isolated yields (85-98\%) and enantiomeric excesses (96-98\%) were obtained. We performed several of these reactions on multi-mmol scale in order to assess the scalability and overall robustness of the method. All four substrates studied (3a, $\mathbf{3 b}, \mathbf{3 g}$ and $\mathbf{3 r}$, Table $\mathbf{2}$ ) yielded the desired products in nearly identical yields on the gram scale. 
Table 2: Catalytic Asymmetric Allylboration of $\alpha$-Aryl $\alpha$-Iminoesters: ${ }^{a, b, c}$

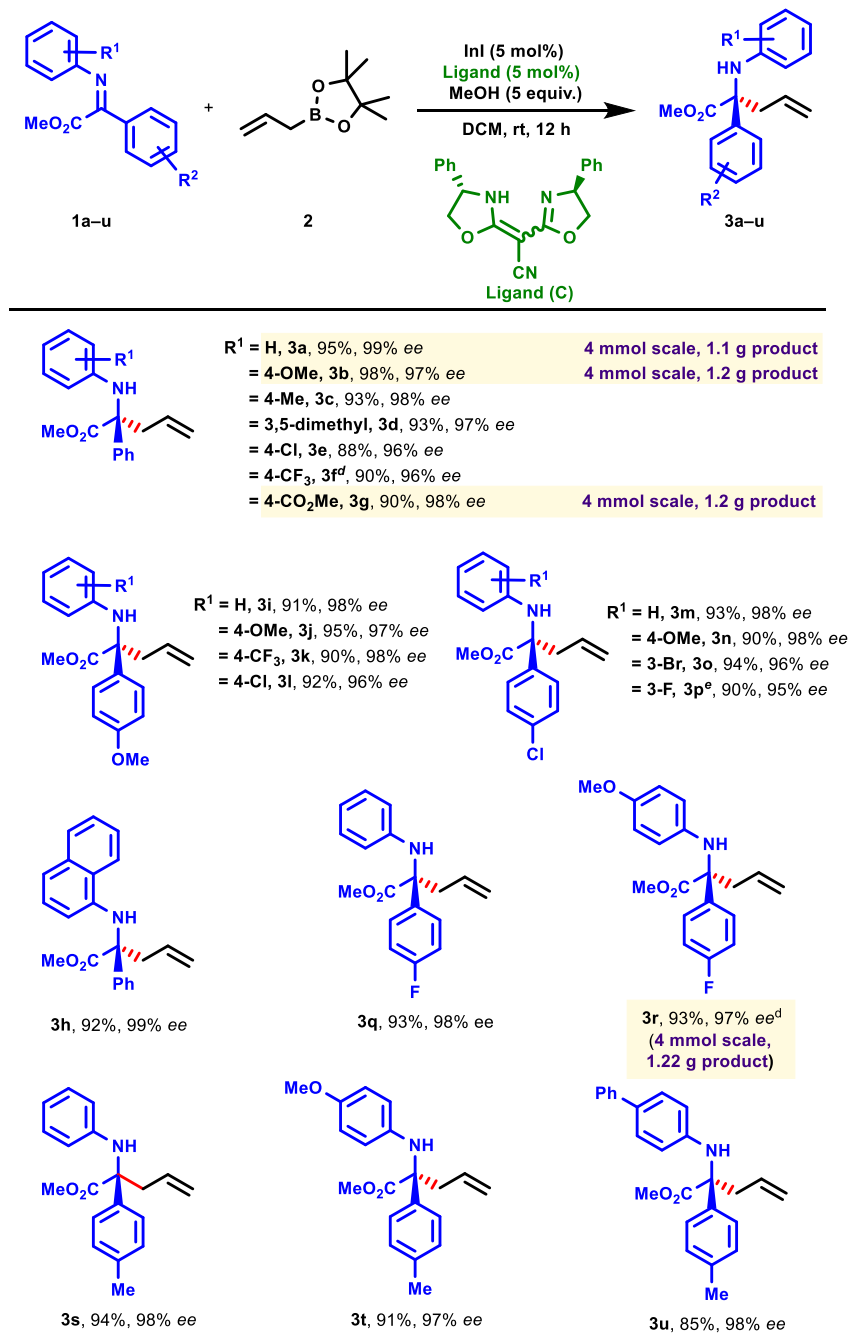

a Conditions: Ketiminoester (1a-1u, 0.5-4.0 mmol), AllylBpin (2, 0.75-6.0 $\mathrm{mmol}), \mathrm{InI}(0.025-0.2 \mathrm{mmol})$, Ligand (0.025-0.2 mmol), MeOH (2.5-20.0 $\mathrm{mmol})$ in $1.5-12.0 \mathrm{~mL}$ of DCM at rt. ${ }^{\text {b }} \mathrm{All}$ the reported yields are isolated yields. ${ }^{\mathrm{c}} \mathrm{All}$ the $e e$-s are determined by HPLC or SFC analysis on chiral stationary phase. ${ }^{\mathrm{d}}$ The $e e$ for compound $\mathbf{3 f}$ was determined by HPLC analysis of the corresponding amino alcohol obtained via hydroboration and oxidation of the olefin. ${ }^{e}$ Reaction took 78 hours to complete; in THF $12 \mathrm{~h}(90 \%$, $93 \% e e$ ).

Next, we optimized the method for catalytic asymmetric allylboration of $\alpha$-trifluoromethyl $\alpha$-iminoesters (see SI p. 14). Slightly higher In(I)I and ligand (C) loadings (10 mol\%) were needed and THF was identified as the best solvent. Using the optimized conditions, ten $\alpha$-trifluoromethyl $\alpha$-iminoesters (Table 3; 4a to $4 \mathbf{i}$ ) were allylated in excellent yields (91-99\%) and enantioselectivities (9099\%). In particular, imine $4 \mathbf{e}$ stood out as it furnished the corresponding homoallylic aminoester product (5e) in $98 \%$ yield and with over $99 \% e e$. Reactions in this series could be readily scaledup to furnish homoallylic amines $\mathbf{5 a}, \mathbf{5 e}$ and $\mathbf{5 h}$ in multi-mmol quantities (Table 3).

We propose a preliminary mechanistic model that accounts for the observed high $S$ stereoselectivity. To construct this model, we assume the following: (1) the allyl group is transferred to indium to give an indium(I) allyl species; (2) the $\alpha$-ketiminoester substrate coordinates as a bidentate ligand and (3) the reaction takes place via a chair-type transition-state around a square pyramidal indium(I) metal center. The commonly invoked steric model has the $\alpha$-ketiminoester bound to the open face of the chiral indium(I) complex, and the smaller allyl group to the sterically more congested site (Figure 2). ${ }^{21}$ This steric model incorrectly predicts the absolute configuration of the major allylation product to be $R$ instead of the experimentally observed $S$ (See SI p. 19, 46). In comparison, an alternative stereochemical model, which invokes attractive interactions, correctly predicts $S$ as the major product. In the attractive model the $\alpha$-ketiminoester group resides on the sterically more hindered site next to a phenyl group of the BOX ligand. This phenyl group can be envisioned to develop attractive interactions to the substrate ketiminoester $\pi$ system. ${ }^{22}$ These attractive interactions potentially lock the substrate in place for the highly selective allyl delivery.
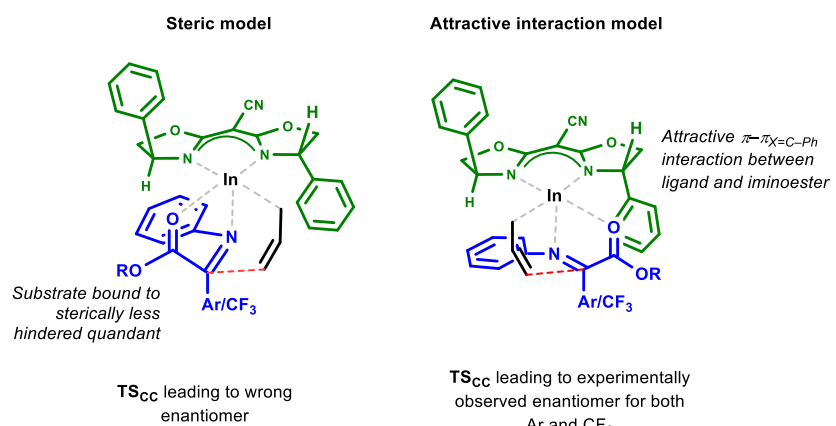

Figure 2. Preliminary stereoselectivity model involves attractive interactions between $\alpha$-ketiminoester and BOX ligand.

Table 3: Catalytic Asymmetric Allylboration of $\alpha$-Trifluoromethyl $\alpha$-Iminoesters: ${ }^{a, b, c}$
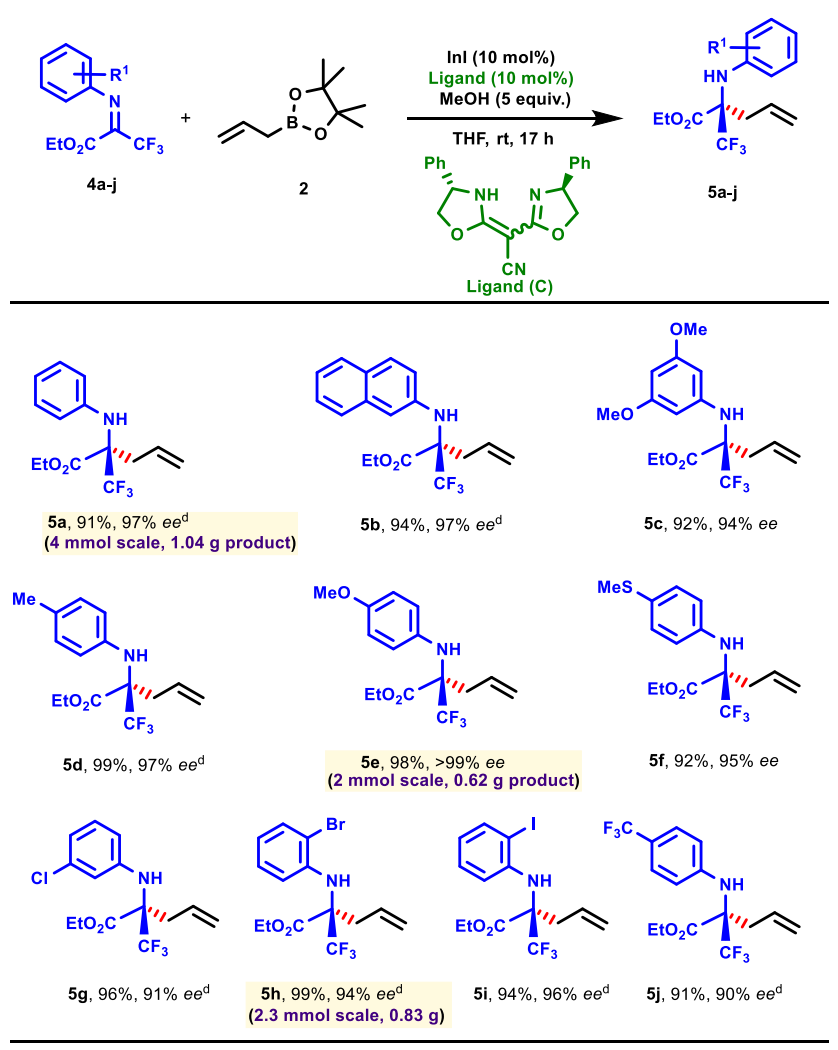

${ }^{\mathrm{a}}$ Conditions: Trifluoroiminoester $(\mathbf{4 a}-\mathbf{4} \mathbf{j}, 0.5-4.0 \mathrm{mmol})$, AllylBpin $(\mathbf{2}$, $0.75-6.0 \mathrm{mmol})$, InI (0.05-0.4 mmol), Ligand (0.05-0.4 mmol), $\mathrm{MeOH}$ $(2.5-20.0 \mathrm{mmol})$ in $1.5-12.0 \mathrm{~mL}$ of THF at $\mathrm{rt}$ for the indicated time. ${ }^{\mathrm{b}} \mathrm{All}$ reported yields are isolated yields. ${ }^{\text {cAll }}$ the $e e$-s are determined by HPLC or SFC analysis on chiral stationary phase. ${ }^{\mathrm{d}}$ The enantiomeric excesses for these compounds were determined by HPLC or SFC analysis of the corresponding amino alcohol. 
Table 4: Change of Ligand Leads to Enantiomeric products: b, c

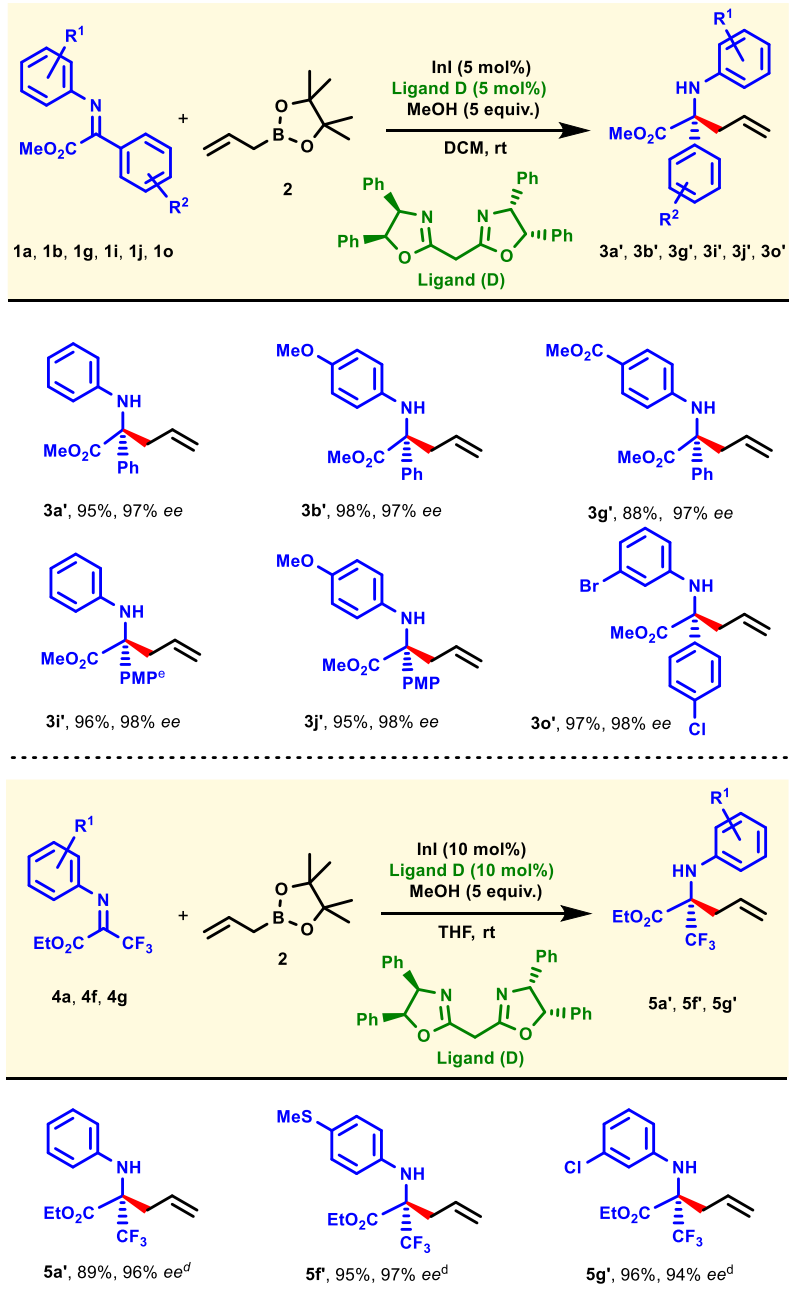

${ }^{\mathrm{a} C o n d i t i o n s: ~ I m i n o e s t e r ~}(0.5 \mathrm{mmol})$, AllylBpin $(2,0.75 \mathrm{mmol}), \mathrm{InI}(0.025$ or $0.05 \mathrm{mmol}$ ), Ligand (0.025 or $0.05 \mathrm{mmol}), \mathrm{MeOH}(2.5 \mathrm{mmol})$ in $1.5 \mathrm{~mL}$ of DCM or THF at rt. ${ }^{b}$ All the reported yields are isolated yields. ${ }^{\mathrm{c}} \mathrm{All}$ the $e e$-s are determined by HPLC or SFC analysis on chiral stationary phase. ${ }^{\mathrm{d}}$ The enantiomeric excesses for these compounds were determined by HPLC or SFC analysis on chiral stationary phase of the corresponding amino alcohol. ${ }^{\mathrm{e}} \mathrm{p}$-Methoxyphenyl.

Ligand ent-C, that would be required for the preparation of the opposite product enantiomer, is not commercially available. Fortuitously, in the initial screening the structurally related BOX-ligand $\mathbf{D}$ performed comparably to ligand $\mathbf{C}$ but reversed the sense of enantio-induction. Using thr commercially available and cheap ligand $\mathbf{D},{ }^{23}$ six different $\alpha$-aryl $(\mathbf{1 a}, \mathbf{1 b}, \mathbf{1 g}, \mathbf{1 i}, \mathbf{1 j}, \mathbf{1 0})$ and three $\alpha$-trifluoromethyl $\alpha$-iminoesters $(\mathbf{4 a}, \mathbf{4 f}, \mathbf{4 j})$ were subjected to the allylation conditions (Table 1, entry 19). In all cases, the opposite enantiomers of the desired homoallylic $\alpha$-aminoester products were isolated in very good to excellent yields and with excellent enantioselectivities (Table 4).

Finally, to demonstrate the method's broader synthetic utility, we used the allylated products to prepare three $\alpha$-substituted $N$-substituted proline ester derivatives 7a, 7b and 9a via sequential hydroboration-oxidation-cyclization (Scheme 2). This short sequence provides convenient access to a range of important $\alpha$-substituted prolines, especially biologically and biochemically important $\alpha$-trifluoromethylproline. ${ }^{24}$ Similar densely functionalized pyrrolidine moieties are also ubiquitous substructures in many natural products, ${ }^{25}$ drugs, ${ }^{26}$ and organocatalysts. ${ }^{27}$
Scheme 2: Transformations of the Chiral Homoallylic Amine Products into $\alpha$-substituted Proline esters:

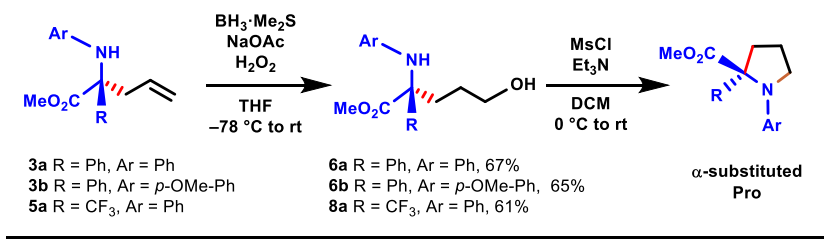

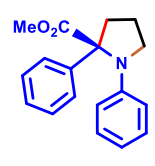

$7 a, 87 \%$

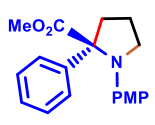

7b, $76 \%$

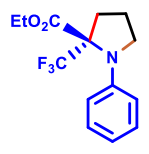

9a, $77 \%$
In summary, we have developed a direct catalytic asymmetric allylboration of $\alpha$-aryl and $\alpha$-trifluoromethyl ketiminoesters using chiral In(I) complexes. The structurally diverse allylated products are highly enantioenriched, and the sense of absolute stereochemistry can be selected by simply switching between two commercially available BOX-type ligands. This work demonstrates how a catalytic enantioselective method can be conveniently rendered enantiodivergent by employing two structurally-related catalysts instead of having to use the enantiomers of a single catalyst. The optimized allylation reactions are operationally simple and both can be carried out on gram-scale without the need to extensively exclude air and moisture. Furthermore, we have also demonstrated the broader synthetic utility of the allylated products as chiral building blocks for the construction of $\alpha$-substituted proline derivatives. We expect these allylated products to be versatile starting materials for the synthesis of various other heterocycles. In-depth computational and experimental studies to better understand the stereoselectivity controlling factors of the reaction are ongoing in our laboratories.

\section{ASSOCIATED CONTENT}

Complete experimental procedures and characterization data including ${ }^{1} \mathrm{H}$ and ${ }^{13} \mathrm{C}$ NMR spectra and chromatograms. This material is available free of charge via the Internet at http://pubs.acs.org.

\section{AUTHOR INFORMATION}

\section{Corresponding Author}

kurti.laszlo@rice.edu

\section{Notes}

The authors declare no competing financial interest.

\section{ACKNOWLEDGMENT}

L.K. gratefully acknowledges the generous financial support of Rice University, the National Institutes of Health (R01 GM114609-04), the National Science Foundation (CAREER:SusChEM CHE-1546097), the Robert A. Welch Foundation (grant C-1764), Amgen (2014 Young Investigators' Award for L.K.) and Biotage (2015 Young Principal Investigator Award) that are greatly appreciated. J.H.S gratefully acknowledges the support from Wiess Teaching Postdoctoral fund.

\section{REFERENCES}

1. a) Xie, W.; Zou, B.; Pei, D.; Ma, D. Total Synthesis of Cyclic Tetrapeptide FR235222, a Potent Immunosuppressant that Inhibits Mammalian Histone Deacetylases. Org. Lett. 2005, 7, 2775-2777. b) Ohfune, Y.; Shinada, T. Enantio- and Diastereoselective Construction of $\alpha, \alpha$-Disubstituted $\alpha$-Amino Acids for the Synthesis of Biologically 
Active Compounds. Eur. J. Org. Chem. 2005, 24, 5127-5143. and references therein

2. a) Savage, S. A.; Waltermire, R. E.; Campagna, S.; Bordawekar, S.; Toma, J. D. R. Development and Large-Scale Preparation of an Oral TACE Inhibitor. Org. Process Res. Dev. 2009, 13, 510-518. (b) Washburn, W. N.; et al. BMS-201620: a selective beta 3 agonist. Bioorg. Med. Chem. Lett. 2004, 14, 3525-3529. (c) Ma, D. W.; Tian, H. Q.; Zou, G. X. Asymmetric Strecker-Type Reaction of $\alpha$-Aryl Ketones. Synthesis of $(S)-\alpha \mathrm{M} 4 \mathrm{CPG},(S)$-MPPG, $(S)$-AIDA, and $(S)$ APICA, the Antagonists of Metabotropic Glutamate Receptors. $J$. Org. Chem. 1999, 64, 120-125. (d) Stilz, H. U.; Jablonka, B.; Knolle, J.; Paulus, E. F.; Zoller, G. Discovery of an Orally Active Non-Peptide Fibrinogen Receptor Antagonist. J. Med. Chem. 1996, 39, 2118 2122.

3. a) Fluorine in Medicinal Chemistry and Chemical Biology. Ojima, E., (Ed.) Wiley-Blackwell: 2009. and references therein

4. (a) Graver, A.; Konig, B. Peptidomimetics - A Versatile Route to Biologically Active Compounds. Eur. J. Org. Chem. 2009, 30, 50995111. (b) Venkatraman, J.; Shankaramma, S. C.; Balaram, P. Design of Folded Peptides Chem. Rev. 2001, 101, 3131-3152.

5. (a) Hughes, A. B. Amino Acids, Peptides and Proteins in Organic Chemistry. Wiley: Weinheim, 2009; (b) Barrett, G. C.; Elmore, D. T. Amino Acids and Peptides. University Press: Cambridge, 1998. (c) Nagaraj, R.; Balaram, P. Alamethicin, a transmembrane channel Acc. Chem. Res. 1981, 14, 356-362. (d) Yokum, T. S.; Gauthier, T. J.; Hammer, R. P.; McLaughlin, M. L. Solvent Effects on the $33_{10} / \alpha-H e-$ lix Equilibrium in Short Amphipathic Peptides Rich in $\alpha, \alpha$-Disubstituted Amino Acids J. Am. Chem. Soc. 1997, 119, 1167-1168. (e) Kato, T.; Oba, M.; Nishida, K.; Tanaka, M. Cell-Penetrating Helical Peptides Having ${ }_{\mathrm{L}}$-Arginines and Five-Membered Ring $\alpha, \alpha$-Disubstituted $\alpha$-Amino Acids Bioconjugate Chem. 2014, 25, 1761-1768. (f) Szekeres, A.; Leitgeb, B.; Kredics, L.; Antal, Z.; Hatvani, L.; Manczinger, L.; Vagvolgyi, C. Peptaibols and related peptaibiotics of Trichoderma: A review Acta Microbiol. Immunol. Hung. 2005, 52, 137-168.

6. a) Eftekhari-Sis, B.; Zirak, M. Arylglyoxals in Synthesis of Heterocyclic Compounds Chem. Rev. 2017, 117, 8326-8419. b) Yus, M.; Gonzalez-Gomez, J. C.; Foubelo, F. Catalytic Enantioselective Allylation of Carbonyl Compounds and Imines Chem. Rev. 2011, 111, 77747854.

7. Curto, J. M.; Dickstein, J. S.; Berritt, S.; Kozlowski, M. C. Asymmetric Synthesis of $\alpha$-Allyl- $\alpha$-Aryl $\alpha$-Amino Acids by Tandem Alkylation/ $\pi$-Allylation of $\alpha$-Iminoesters. Org. Lett. 2014, 16, 1948-1951.

8. Riant, O.; Hannedouche, J. Asymmetric Catalysis for the Construction of Quaternary Carbon Centers: Nucleophilic Addition on Ketones and Ketimines Org. Biomol. Chem. 2007, 5, 873-888.

9. Yeung, K.; Talbot, F. J. T.; Howell, G. P.; Pulis, A. P.; Procter, D. J. Copper-Catalyzed Borylative Multicomponent Synthesis of Quaternary $\alpha$-Amino Esters ACS Catal. 2019, 9, 1655-1661.

10. Chaume, G.; Van Severen, M.; Marinkovic, S.; Brigaud, T. Straightforward Synthesis of $(S)$ - and $(R)-\alpha$-Trifluoromethyl Proline from Chiral Oxazolidines Derived from Ethyl Trifluoropyruvate $\mathrm{Org}$. Lett. 2006, 8, 6123-6126.

11. Min, Q.; He, C.; Zhoub, H.; Zhang, X. Highly Diastereoselective Synthesis of Quaternary $\alpha$-Trifluoromethyl $\alpha$-Amino Acids from Chiral Imines of Trifluoropyruvate Chem. Commun. 2010, 46, 8029-8031.

12. Berger, R.; Duff, K., Leighton, J. L. Enantioselective Allylation of Ketone-Derived Benzoylhydrazones: Practical Synthesis of Tertiary Carbinamines J. Am. Chem. Soc. 2004, 126, 5686-5687.

13. Reyes-Rangel, G.; Bandala, Y.; García-Flores, F.; Juaristi, E. Asymmetric Allylation of $\alpha$-Ketoester-Derived N-Benzoylhydrazones Promoted by Chiral Sulfoxides/ $N$-Oxides Lewis Bases: Highly Enantioselective Synthesis of Quaternary $\alpha$-Substituted $\alpha$-Allyl- $\alpha$-Amino Acids Chirality 2013, 25, 529-540.

14. Naodovic, M.; Wadamoto, M.; Yamamoto, H. Enantioselective AgCatalyzed Allylation of Aldimines Eur. J. Org. Chem. 2009, 30, 5129-5131.
15. Wada, R.; Shibuguchi, T.; Makino, S.; Oisaki, K.; Kanai, M.; Shibasaki, M. Catalytic Enantioselective Allylation of Ketoimines J. Am. Chem. Soc. 2006, 128, 7687-7691.

16. Jiang, Y.; Schaus S. E. Asymmetric Petasis Borono-Mannich Allylation Reactions Catalyzed by Chiral Biphenols Angew. Chem. Int. Ed. 2017, 56, 1544-1548.

17. Chakrabarti, A.; Konishi, H.; Yamaguchi, M.; Schneider, U.; Kobayashi, S. Indium(I)- Catalyzed Asymmetric Allylation, Crotylation, and $\alpha$-Chloroallylation of Hydrazones with Rare Constitutional and High Configurational Selectivities. Angew. Chem., Int. Ed. 2010, 49, 1838-1841.

18. a) Schneider, U.; Chen, I.-H.; Kobayashi, S. Development of General Catalytic Allylation of Acylhydrazones with Pinacolyl Allyl Boronate Using an Indium(I) Catalyst. Org. Lett. 2008, 10, 737-740 b) Kobayashi, S.; Konishi, H.; Schneider, U. Indium(I) Iodide-Catalyzed Regio- and Diastereoselective Formal $\alpha$-Addition of an $\alpha$-Methylallyl Boronate to $N$-Acylhydrazones. ChemComm 2008, 20, 2313-2315.

19. Schneider, U.; Kobayashi, S. Low-Oxidation State Indium-Catalyzed C-C Bond Formation Acc. Chem. Res. 2012, 45, 1331-1344.

20. a) Desimoni, G.; Giuseppe, F.; Jørgensen, K. A. $C_{2}$-Symmetric Chiral Bis(Oxazoline) Ligands in Asymmetric Catalysis Chem. Rev. 2006, 106, 3561-3651 Desimoni, G.; Giuseppe, F.; Jørgensen, K. A. Update 1 of: $C_{2}$-Symmetric Chiral Bis(Oxazoline) Ligands in Asymmetric Catalysis Chem. Rev. 2011, 111, PR284-PR437.

21. a) Evans, D. A.; Barnes, D. M.; Johnson, J. S.; Letcka, T.; von Matt, P.; Miller, S. J.; Murry, J. A.; Norcross, R. D.; Shaughnessy, E. A.; Campos, K. R. Bis(oxazoline) and Bis(oxazolinyl)pyridine Copper Complexes as Enantioselective Diels-Alder Catalysts: Reaction Scope and Synthetic Applications J. Am. Chem. Soc. 1999, 121, 75827594. b) Evans, D. A.; Rovis, T.; Kozlowski, M. C.; Tedrow, J. S. $C_{2^{-}}$ Symmetric $\mathrm{Cu}$ (II) Complexes as Chiral Lewis Acids. Catalytic Enantioselective Michael Addition of Silylketene Acetals to Alkylidene Malonates. J. Am. Chem. Soc. 1999, 121, 1994-1995. c) Evans, D. A.; Rovis, T.; Kozlowski, M. C.; Downey, W. C.; Tedrow, J. S. Enantioselective Lewis Acid Catalyzed Michael Reactions of Alkylidene Malonates. Catalysis by $C_{2}$-Symmetric Bis(oxazoline) Copper(II) Complexes in the Synthesis of Chiral, Differentiated Glutarate Esters. J. Am. Chem. Soc. 2000, 122, 9134-9142.

22. For similar cases, see a) Ginotra, S. K.; Singh, V.K. Studies on enantioselective allylic oxidation of olefins using peresters cat-alyzed by $\mathrm{Cu}(\mathrm{I})$-complexes of chiral pybox ligands. Org. Biomol. Chem., 2006, 4, 4370-4374. b) Zhong, F.; Pöthig, A.; Bach, T. Synergistic Stereocontrol in the Enantioselective Ruthenium-Catalyzed Sulfoxidation of Spirodithiolane-Indolones. Chem. Eur. J. 2015, 21, 10310-10313. c) Shao, W.; Wang, Y.; Yang, Z.-P.; Zhang, X.; You, S.-L. Efficient Synthesis of $\mathrm{N}$-Alkylated 4-Pyridones by Copper-Catalyzed Intermolecular Asymmetric Propargylic Amination. Chem. Asian J. 2018, 13, 1103-1107.

23. Both ligand $\mathbf{C}$ and $\mathbf{D}$ are available from Sigma-Aldrich at USD 247/1 $\mathrm{g}$ and USD 305/1 g, respectively. The opposite enantiomer of ligand C is not commercially available.

24. Simon, J.; Pytkowicz, J.; Lensen, N.; Chaume, G.; Brigaud, T. Incorporation of Trifluoromethylated Proline and Surrogates into Peptides: Application to the Synthesis of Fluorinated Analogues of the Neuroprotective Glycine-Proline-Glutamate (GPE) Tripeptide. J. Org. Chem. 2016, 81, 5381-5392.

25. a) D. O'Hagan Pyrrole, Pyrrolidine, Pyridine, Piperidine, Azepine and Tropane Alkaloids Nat. Prod. Rep. 1997, 14, 637-651. b) D. O'Hagan Pyrrole, Pyrrolidine, Pyridine, Piperidine, Azepine and Tropane Alkaloids Nat. Prod. Rep. 2000, 17, 435-446. c) Li, X.; Li, J. Recent Advances in the Development of MMPIs and APNIs Based on the Pyrrolidine Platforms Mini-Rev. Med. Chem. 2010, 10, 794-805.

26. a) Fukui, H.; Shibata, T.; Naito, T.; Nakano, J.; Maejima, T.; Senda, H.; Iwatani, W.; Tatsumi, Y.; Suda, M.; Arika, T. Synthesis and Antibacterial Activity of Novel 7-(3-Substituted-3 or 4-Trifluoromethyl1-Pyrrolidinyl)-8-Methoxyfluoroquinolones Bioorg. Med. Chem. Lett. 1998, 8, 2833-2838. b) Jlalia, I.; Lensen, N.; Chaume, G.; Dzhambazova, E.; Astasidi, L.; Hadjiolova, R.; Bocheva, A.; Brigaud, T. Synthesis of an MIF-1 Analogue Containing Enantiopure $(S)-\alpha-$ 
Trifluoromethyl-Proline and Biological Evaluation on Nociception Eur. J. Med. Chem. 2013, 62, 122-129.

27. a) Fache, F.; Schulz, E.; Tommasino, M. L.; Lemaire, M. NitrogenContaining Ligands for Asymmetric Homogeneous and Heterogeneous Catalysis Chem. Rev. 2000, 100, 2159-2231. b) Mukherjee, S.;
Yang, J. W.; Hoffmann, S.; List, B. Asymmetric Enamine Catalysis Chem. Rev. 2007, 107, 5471-5569. 


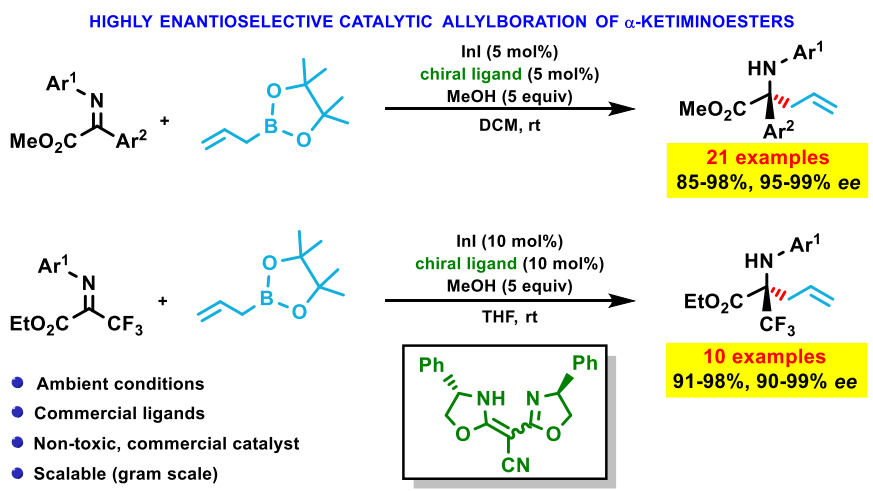

